\title{
Retrieval of Video Contents based on Deep Parameter Analysis using Machine Learning
}

\author{
Mallikharjuna Lingam K, VSK Reddy
}

\begin{abstract}
In the recent past, video content-based communication hasincreases with a significant consumption of space and time complexity. The introduction of the data is exceedingly improved in video information as the video information incorporates visual and sound data. The mix of these two kinds of information for a single data portrayal is exceedingly compelling as the broad media substance can make an ever-increasing number of effects on the human cerebrum. Thus, most of the substance for training or business or restorative area are video-based substances. This development in video information have impacted a significant number of the professional to fabricate and populate video content library for their use. Hence, retrieval of the accurate video data is the prime task for all video content management frameworks. A good number of researches are been carried out in the field of video retrieval using various methods. Most of the parallel research outcomes have focused on content retrieval based on object classification for the video frames and further matching the object information with other video contents based on the similar information. This method is highly criticised and continuously improving as the method solely relies on fundamental object detection and classification using the preliminary characteristics. These characteristics are primarily depending on shape or colour or area of the objects and cannot be accurate for detection of similarities. Hence, this work proposes, a novel method for similarity-based retrieval of video contents using deep characteristics. The work majorly focuses on extraction of moving objects, static objects separation, motion vector analysis of the moving objects and the traditional parameters as area from the video contents and further perform matching for retrieval or extraction of the video data. The proposed novel algorithm for content retrieval demonstrates $98 \%$ accuracy with $90 \%$ reduction in time complexity.
\end{abstract}

Keywords - Object Separation, Regeneration of regions, moving objects detection, frame of reference stabilization, frame rate calibration

\section{INTRODUCTION}

The simplicity of compelling registering is an exploration course, which progresses in the direction of enabling processing gadgets for human knowledge. One of the very well-known human method of correspondence is articulation with verbal correspondence. The articulations as a rule incorporate hand signal, body pose and the outward appearance. For making the figuring gadgets at per with the human knowledge, the consideration of capacities to translate video substances. The uses of video contents are not

Revised Manuscript Received on September 25, 2019

Mallikharjuna Lingam K: Research Scholar, Faculty of Engineering, Lincoln University College, Malaysia

VSK Reddy: Professor, Faculty of Engineering, Lincoln University College, Malaysia. limited to the communication purposes, rather for surveillances as well. The work of A. Ekermo et al. [1] have demonstrated the demand for advanced retrieval of the video contents of the surveillance data as well. The traditional method demonstrates the use of PCA as proposed by Y. M. E. Candes et al. [2] for extraction of the objects in the video frames and also for the matching process during the retrieval of the video data [Fig -1$]$.

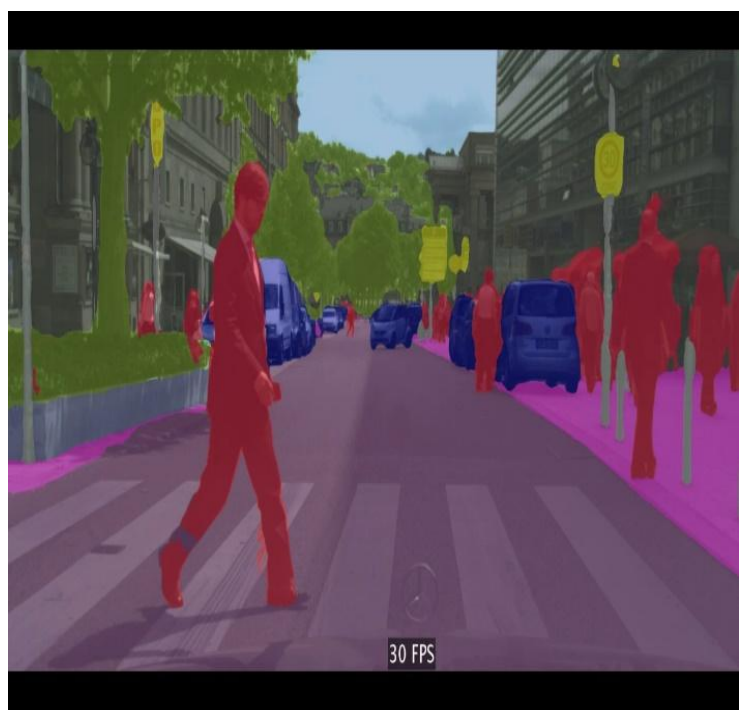

Fig. 1PCA for Object Separation

The advancement of the traditional PCA method was proposed by C. Lu et al. [3] and X. Liu et al. [4] for increasing the ranking method of the matched video contents. This method is criticised for under consideration of the moving objects, which was again proposed by X. Zhou et al. [5]. The proposed work by X. Zhou et al. [5] also proposes to reduce the out lairs from the video data during the retrieval process. Nonetheless, the recent development in the capture devices have demonstrated significant reduction of noises and increase in stabilization of the video contents. Hence, the higher complexity of this work cannot be justified in present situations.

Thus, this work proposes a novel strategy for reduction in the time complexity with enhancement of accuracy and reliability of the retrieved video contents based on deep characteristics extraction process. The rest of the work is organized as in Section - II the fundamentals of parametric video content retrieval process is elaborated, in the Section III the parallel research outcomes are discussed, in Section - IV the formulation

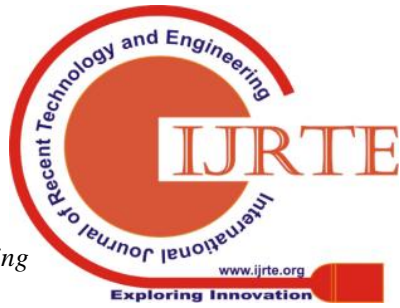


of the problem using mathematical modelling is presented, in Section $-\mathrm{V}$ the proposed algorithms are furnished and elaborated, in Section - VI the results obtained from the proposed algorithms are discussed and the work presents the research conclusion on Section - VII.

\section{VIDEO CONTENT RETRIEVAL FUNDAMENTALS}

In this section of the work, the fundamental principle of video content retrieval is discussed and mathematically analysed.

Assuming that the complete video library, V[], contains multiple video content files, $\mathrm{v}_{\mathrm{x}}$, then the relation can be formulated as,

$$
V[]=\sum_{i} v_{i}
$$

During the video content retrieval process, for advanced searching method, the input video content is matched with the video library and the matching contents are returned. Assuming that the searching or the input content is $v_{x}$, then as a preliminary step, the objects, Obj[], from the search input video contents will be retrieved,

$$
v_{x} \rightarrow f(O b j[])
$$

The extracted object set is again collection of many objects appearing on different time frames, $t$, thus,

$$
\operatorname{Obj}[]=\sum_{n} \operatorname{Obj}_{n}(t)
$$

Again, each and every object is collection of traditional objects matching properties, as

\section{III.PARALLEL RESEARCH OUTCOMES}

After the detailed realization of the fundamental principle of the video content retrieval process, in this section of the work the parallel research outcomes are reviewed.

The accuracy and improvement of the accuracy for the video retrieval process relies primarily on the object detection and separation for any video frames. The recent research, as demonstrated by X. Zhang et al. [6], have focused not only on the static object detection, rather on the moving objects detection as well.

The bottleneck of the moving object detection is the calibration of the capture devices. Many recent research outcomes have demonstrated that the capture devices can be static, but due to the dynamic focus properties, the capture devices can appear as dynamic. Hence, the stabilization of the video object references for moving objects can be considered. The work by O. Oreifej et al. [7] ensure the stabilization of the frames during moving object detection.

After the detection of the moving objects, it is also mandatory that the area for the moving objects must be detected. This detection of area ensures that, the change in characteristics of any object from static to moving can also be detected. The work by W. Cao et al. [8] and X. Cao et al. [9] demonstrates the process of object area detection using background separation. This work is also criticised for being highly dependent on image saturation and colour intensity variation during the change in lighting conditions. The enhancement of this work is proposed by H. Yong et al. [10] and L. Li et al. [11].

Considering the bottlenecks of these parallel research outcomes, this work proposes the novel improvements in the further section of this work.

$$
\mathrm{Obj}_{x} \rightarrow f(\text { Color, Shape, Orientation, Location) (Eq.4) }
$$

\section{IV.PROBLEM FORMULATION}

Henceforth, the object properties, $O b j_{x}$, is matched with the complete video content library and the matching video contents are returned based on the threshold, $\Delta T h$. This can be presented as,

$$
V_{y}\left\{\operatorname{Obj}_{y}(t)\right\} \leftarrow \leftarrow \frac{V[]\left\{O \operatorname{Obj}_{x}(t)\right\}}{\Delta \operatorname{Th}\left\{V[]\left(O b j_{x}\right)\right\}}
$$

Due the limitation of the video contents matching properties, which highly depends on the external factors, and cannot retrieve accurate video contents as search results, this work proposed a novel approach based on deep machine learning method using deep extraction of the properties.

THE FORMULATION OF THE MATHEMATICAL LEMMA AS A PROOF IS PRESENTED IN THE FURTHER SECTION OF THIS WORK.
After the detailed analysis of the parallel research outcomes, in this section of the work, the problem formulation is carried out with possible solutions.

Lemma - 1: Deep extraction of the video content properties can increase the accuracy of the video content retrieval process.

Proof: In order to proof the above lemma, this work formulates the following steps using mathematical modelling technique.

As stated in the basic principle in the video content retrieval process, it is assumed that for the input video content, $\mathrm{v}_{\mathrm{x}}$, the matching video content, $\mathrm{v}_{\mathrm{y}}$, must be retrieved. 
Hence, firstly, the deep parameters must be extracted from the input or searching video content as Static_Objects, S[], Moving_Object, M[], Fast_Moving_Object, FM[] and Object_Area, A[].

Thus, the extraction process of the Static_Objectsfrom the video contents can be formulated as,

$$
\Phi\left[v_{x}\right] \rightarrow S[]
$$

And, detection of the Moving_Object from the video contents can be formulated as,

$$
\Phi^{\prime}\left[v_{x}\right] \rightarrow M[]
$$

Here assuming that, detection process, in the traditional method, is only consisting of the objects without any classifications, then the accuracy can be formulated as,

$$
\frac{v_{x}}{v_{y}} \rightarrow \frac{f(\operatorname{Obj}[])}{\sum_{i} f(\operatorname{Obj}[])_{i}} \rightarrow \alpha
$$

Again, using the deep properties of the video contents, as proposed in this work, can be formulated as,

$$
\frac{v_{x}}{v_{y}} \rightarrow \frac{\Phi\left[v_{x}\right] \cdot \Phi^{\prime}\left[v_{x}\right]}{\sum_{i}\left\{\Phi\left[v_{y}\right] \cdot \Phi^{\prime}\left[v_{y}\right]\right\}_{i}} \rightarrow \gamma
$$

Here it is natural to realize that,

$$
\alpha<\gamma(\text { Eq.10) }
$$

As, the number of classifications of the objects in Eq. 8 is less than Eq. 9.

Secondly, the extraction of the faster moving objects from the video content can be formulated as,

$$
\Phi_{1}^{\prime}\left[v_{x}\right] \rightarrow F M[]
$$

And, the remaining moving objects can be formulated as,

$$
\Phi^{\prime}\left[v_{x}\right]-\Phi_{1}^{\prime}\left[v_{x}\right] \rightarrow \Phi_{2}^{\prime}\left[v_{x}\right]
$$

Hence, Eq. 9 can be reformed as,

$$
\frac{v_{x}}{v_{y}} \rightarrow \frac{\Phi\left[v_{x}\right] \cdot \Phi_{1}^{\prime}\left[v_{x}\right] \cdot \Phi_{2}^{\prime}\left[v_{x}\right]}{\sum_{i}\left\{\Phi\left[v_{y}\right] \cdot \Phi_{1}^{\prime}\left[v_{y}\right] \cdot \Phi_{2}^{\prime}\left[v_{y}\right]\right\}_{i}} \rightarrow \vartheta
$$

Further, this will increase the detection accuracy and can be presented as,

$$
\alpha<\gamma<\vartheta
$$

Finally, the area for the faster moving objects can be identified as,

$$
\Upsilon\left[\Phi_{1}^{\prime}\left[v_{x}\right]\right]+\Upsilon\left[\Phi_{2}^{\prime}\left[v_{x}\right]\right] \rightarrow A[]
$$

Hence, Eq. 13 can be re-written as,

$$
\frac{v_{x}}{v_{y}} \rightarrow \frac{\Phi\left[v_{x}\right] \cdot \frac{\Phi_{1}^{\prime}\left[v_{x}\right] \cdot \Phi_{2}^{\prime}\left[v_{x}\right]}{\Upsilon\left[\Phi_{1}^{\prime}\left[v_{x}\right]\right]+\Upsilon\left[\Phi_{2}^{\prime}\left[v_{x}\right]\right]}}{\sum_{i}\left\{\Phi\left[v_{y}\right] \cdot \frac{\Phi_{1}^{\prime}\left[v_{y}\right] \cdot \Phi_{2}^{\prime}\left[v_{y}\right]}{\Upsilon\left[\Phi_{1}^{\prime}\left[v_{y}\right]\right]+\Upsilon\left[\Phi_{2}^{\prime}\left[v_{y}\right]\right]}\right\}_{i}} \rightarrow \Omega(\text { Eq. 16) }
$$

Naturally,

$$
\alpha<\gamma<\vartheta<\Omega
$$

Hence, it is proven that, the inclusion of the deep properties of the video content can increase the accuracy of the video retrieval process.

Based on this proof, in the next section of the work, the proposed novel algorithm is furnished.

\section{Proposed Novel Deep Parameter Analysis ALGORITHM FOR VIDEO RETRIEVAL}

In this section of the work, a total of four algorithms are discussed. The first algorithm separates the static objects from the video frames and stores for further analysis. The second algorithm detects the moving objects in the video frame. The third algorithm detects the area of the moving objects and the final algorithm performs the matching factor calculations for video content retrieval.

Algorithm - 1: Static Object Detection using
Region Regeneration (SOD-RR)
Step - 1. Accept the video data as V[]
Step - 2. Split the video data into frames as
VF[][]
Step - 3. For each VF[i][]
a. Detect each frame as VF[i][j]
b. For each frame in VF[i][j]
i.Detect the regions using the WaterShed
method for total regions = $\mathrm{n}$
ii.Build the region set as VF[i][j][k]
iii.For each VF[i][j][k]
1. Calculate the region pixel density as I
2. Identity the mean difference of intensity
for each region
3. If Mean (I) <Intensity(VF[i][j][k])
Then
a.Break VF[i][j][k] into further regions as
VF[i][j][k+n+1]
b.Repeat from Step - 3.B.III
c.Count the region as Object and store in
Obj[x]
4. Return Obj[]
Published By:
\&lue Eyes Intelligence Engineering
\&ciences Publication


Each item class has its very own extraordinary highlights that aides in arranging the class - for instance, all circles are round. Item class identification utilizes these extraordinary highlights. For instance, when searching for circles, protests that are at a specific separation from a point are looked for. Correspondingly, when searching for squares, protests that are opposite at corners and have equivalent side lengths are required. A comparable methodology is utilized for face distinguishing proof where eyes, nose, and lips can be found and highlights like skin shading and separation between eyes can be found.

Algorithm - 2: Moving and Faster Moving Object Detection using Frame Rate Tracking (MFMOD-FRT)

Step - 1. Accept the objects in each video as Obj[x]

Step - 2. For each object in $\mathrm{Obj}[\mathrm{x}]$

a. Calculate the position at time $\mathrm{t} 1$ and at frame $\mathrm{VF}[\mathrm{i}][\mathrm{j}]$

b. Calculate the position at time $\mathrm{t} 2$ and at frame $\mathrm{VF}[\mathrm{i}][\mathrm{j}+\mathrm{n}]$

c. Calculate the distance at pixel by $\bmod \{\mathrm{VF}[\mathrm{i}][\mathrm{j}]-\mathrm{VF}[\mathrm{i}][\mathrm{j}+\mathrm{n}]\}$

d. Calculate the motion, $m$ as $\bmod \{\mathrm{VF}[\mathrm{i}][\mathrm{j}]-$ $\mathrm{VF}[\mathrm{i}][\mathrm{j}+\mathrm{n}]\} /\{\mathrm{t} 2-\mathrm{t} 1\}$

e. If $m>0$

f. Then

$$
\text { i. Identify the } \operatorname{Obj}[\mathrm{x}] \text { as }
$$

Step - 3. Calculate the mean $\mathrm{m}[]$ as $\mathrm{M}$

Step - 4. For each object in Obj[x]
a. If $m>M$
b. Then

$$
\begin{aligned}
& \text { i. Identify the Obj[x] as } \\
& \text { Obj_Fast_Moving[z] }
\end{aligned}
$$

Step - 5. Return Obj_Moving[], Obj_Fast_Moving[]

Moving article identification is a strategy utilized in PC vision and picture handling. Different back to back edges from a video is contrasted by different strategies with deciding whether any moving item is detected. Moving objects location has been utilized for a wide scope of uses like video reconnaissance, human movement investigation, street condition checking, air terminal wellbeing, observing of insurance along marine outskirt and so on.

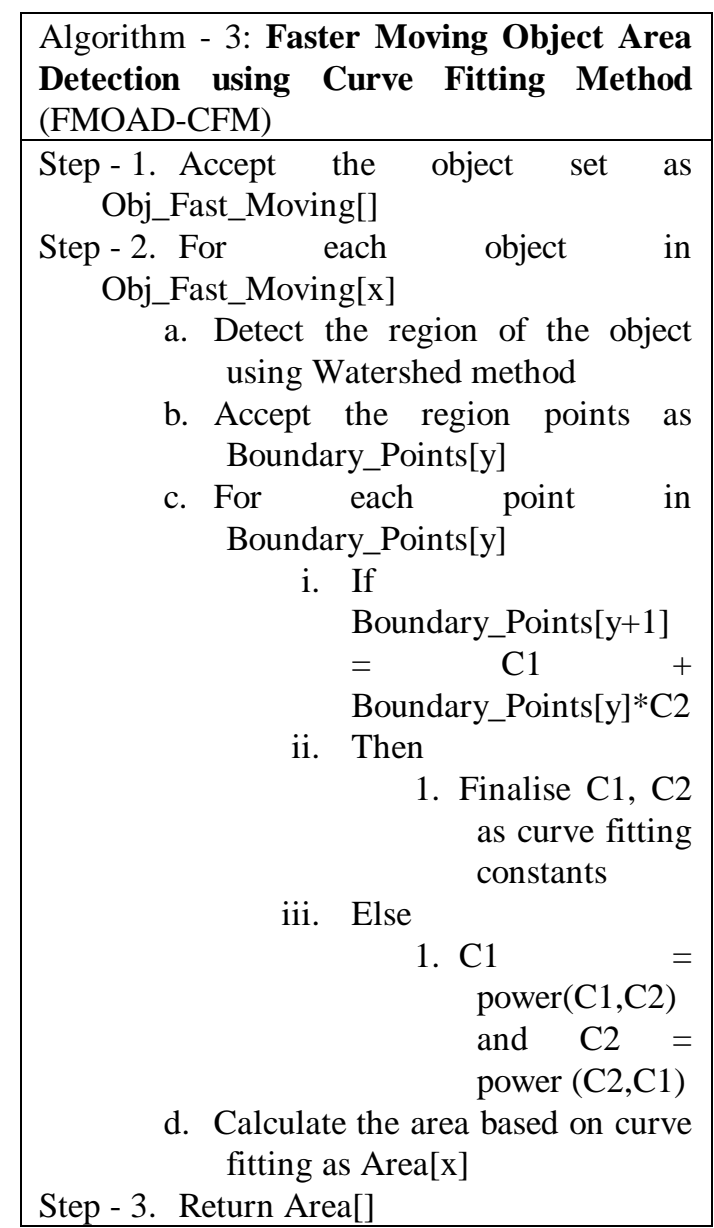

Bend fitting, otherwise called relapse investigation, is utilized to locate the "best fit" line or bend for a progression of information focuses. More often than not, the bend fit will create a condition that can be utilized to discover focuses anyplace along the bend. Now and again, you may not be worried about finding a condition. Rather, you may simply need to utilize a bend fit to smooth the information and improve the presence of your plot.

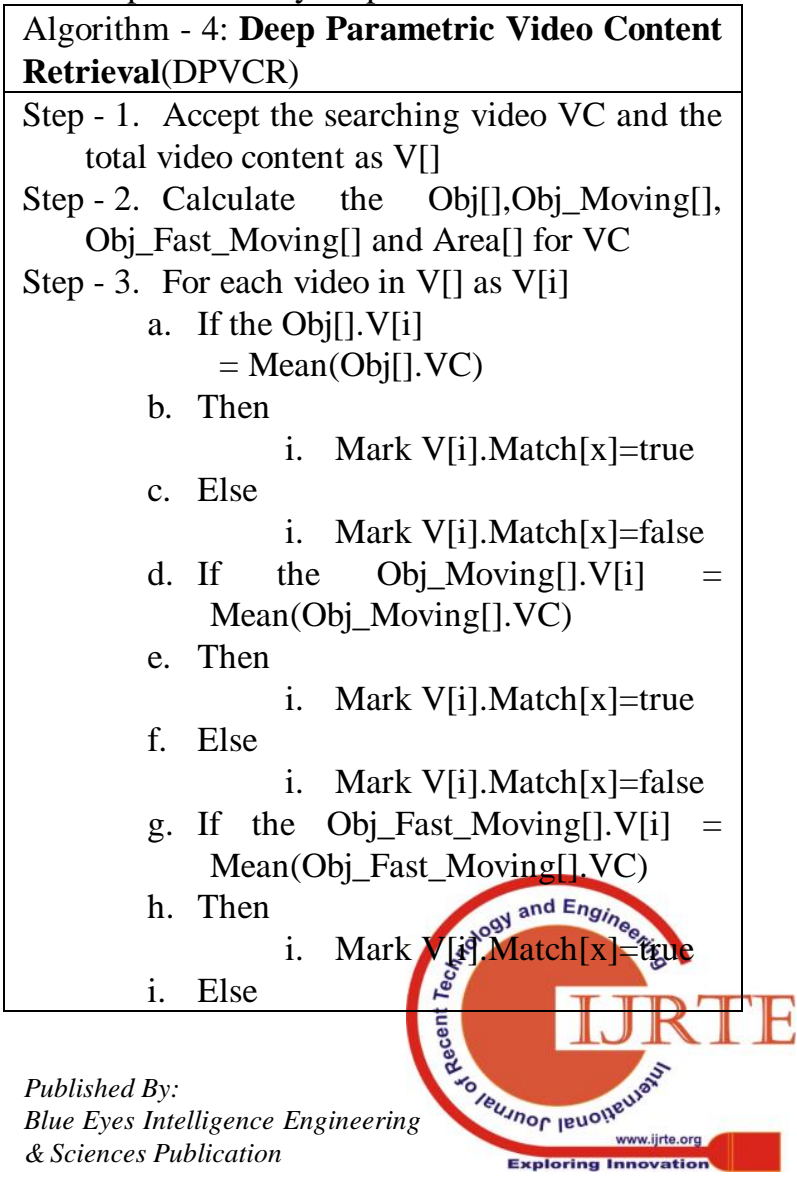




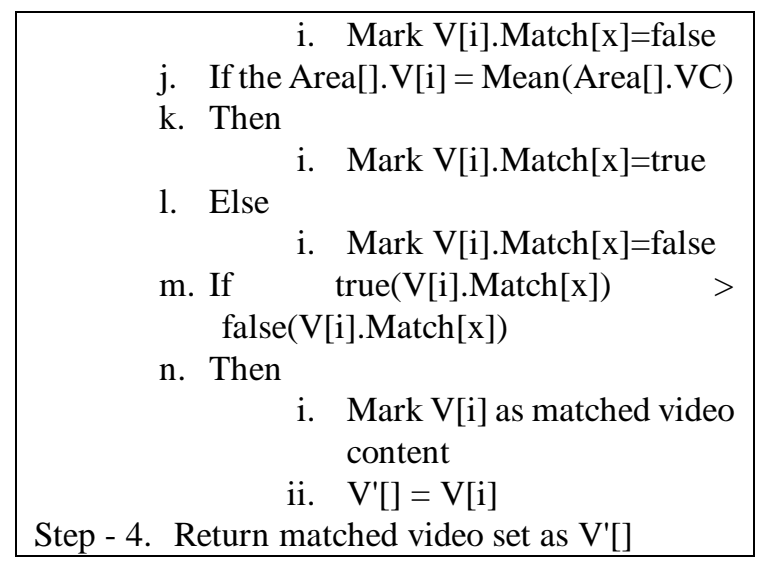

The enthusiasm for CBIR has developed in light of the restriction's characteristic in metadata-based frameworks, just as the huge scope of potential uses for proficient picture recovery. Printed data about pictures can be effectively sought utilizing existing innovation, yet this expects people to physically depict each picture in the database.

The outcomes of these proposed algorithms are discussed in the next section of the work.

\section{RESULTS AND DISCUSSION}

The obtained results from the proposed algorithms are highly satisfiable and are discussed in this section of the work The results are discussed in six sub section as discussion on the used datasets, static object detection, moving object detection, faster moving object analysis, area analysis for the faster moving objects and finally the retrieval algorithm.

\section{A. Dataset Analysis}

The details of the datasets are listed here [Table - 1].

TABLE I

DATASET DESCRIPTION

\begin{tabular}{|c|l|c|l|}
\hline $\begin{array}{l}\text { Serial } \\
\text { Numbe } \\
\mathbf{r}\end{array}$ & $\begin{array}{l}\text { Dataset } \\
\text { Name }\end{array}$ & $\begin{array}{l}\text { Yea } \\
\mathbf{r}\end{array}$ & Generic Characteristics \\
\hline 1 & $\begin{array}{l}\text { BBC } \\
\text { Eastenders }\end{array}$ & 2018 & $\begin{array}{l}\text { Video Dataset with small length } \\
\text { contents for instance retrieval }\end{array}$ \\
\hline 2 & IACC.3 & 2018 & $\begin{array}{l}\text { Video Dataset with contents for } \\
\text { Ad-hoc detection }\end{array}$ \\
\hline 3 & $i-L I D S$ & 2017 & $\begin{array}{l}\text { Video Dataset with surveillance } \\
\text { video contents for key frame } \\
\text { detection based on events }\end{array}$ \\
\hline 4 & Flickr & 2012 & $\begin{array}{l}\text { Video Dataset with small length } \\
\text { contents for instance retrieval }\end{array}$ \\
\hline
\end{tabular}

The algorithms are tested on four different datasets and the results obtained from all datasets are further compared. The use of the standard datasets ensures the correctness of the algorithm.

\section{B. Static Object Analysis}

The details of the static object detection and analysis is listed here [Table - 2].
TABLE II

STATIC OBJECT DETECTION AND ANALYSIS

\begin{tabular}{|c|c|c|c|}
\hline $\begin{array}{l}\text { Dataset } \\
\text { Name }\end{array}$ & $\begin{array}{l}\text { Searchin } \\
\text { g Content } \\
\text { Name }\end{array}$ & $\begin{array}{l}\text { Match Factor } \\
\text { Static Objects } \\
\text { (As low as } \\
\text { better) }\end{array}$ & $\begin{array}{l}\text { Match } \\
\text { Result }\end{array}$ \\
\hline $\begin{array}{c}\text { BBC } \\
\text { Eastender } \\
\mathrm{s}\end{array}$ & $\begin{array}{c}\text { Video } \\
\text { Data - } 1\end{array}$ & 194 & Match \\
\hline Flickr & $\begin{array}{c}\text { Video } \\
\text { Data - } 2\end{array}$ & 194 & Match \\
\hline IACC. 3 & $\begin{array}{c}\text { Video } \\
\text { Data - } 3\end{array}$ & 800 & Match \\
\hline Flickr & $\begin{array}{c}\text { Video } \\
\text { Data - } 4\end{array}$ & 800 & Match \\
\hline $\begin{array}{c}\text { BBC } \\
\text { Eastender } \\
\mathrm{s}\end{array}$ & $\begin{array}{c}\text { Video } \\
\text { Data - } 2\end{array}$ & 994 & Match \\
\hline IACC. 3 & $\begin{array}{c}\text { Video } \\
\text { Data - } 3\end{array}$ & 994 & Match \\
\hline $\begin{array}{c}\text { BBC } \\
\text { Eastender } \\
\mathrm{s}\end{array}$ & $\begin{array}{c}\text { Video } \\
\text { Data - } 4\end{array}$ & 1940 & No Match \\
\hline i-LIDS & $\begin{array}{c}\text { Video } \\
\text { Data - } 1\end{array}$ & 1940 & No Match \\
\hline i-LIDS & $\begin{array}{c}\text { Video } \\
\text { Data - } 3\end{array}$ & 2134 & No Match \\
\hline Flickr & $\begin{array}{c}\text { Video } \\
\text { Data - } 4\end{array}$ & 2134 & No Match \\
\hline IACC. 3 & $\begin{array}{c}\text { Video } \\
\text { Data - } 1\end{array}$ & 2934 & No Match \\
\hline i-LIDS & $\begin{array}{c}\text { Video } \\
\text { Data - } 2\end{array}$ & 2934 & No Match \\
\hline
\end{tabular}

The result is visualized graphically here [Fig - 2].

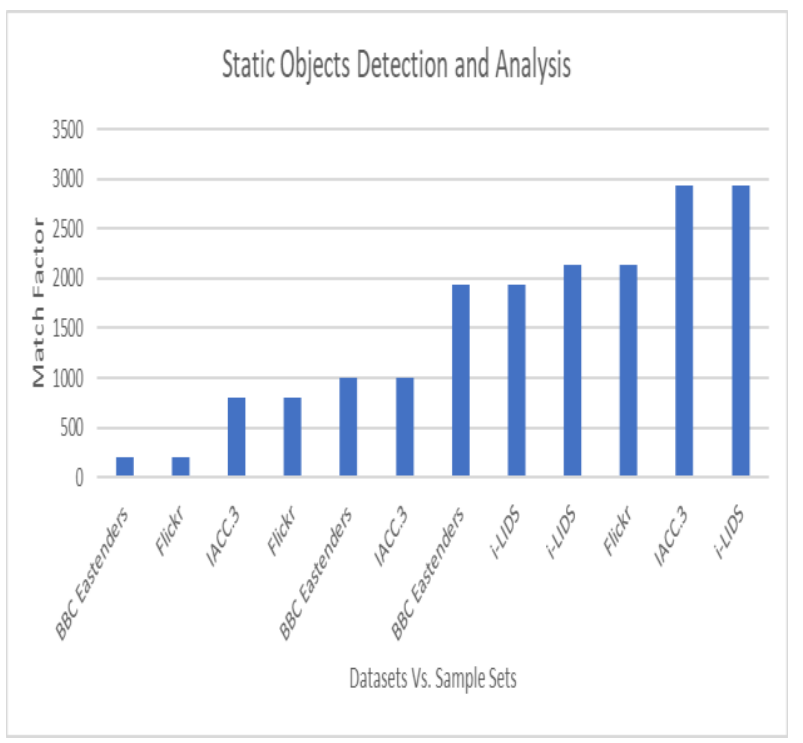

Fig. 2 Static Object Analysis and Match Factor

\section{Moving Object Analysis}

The details of the moving object detection and analysis is listed here [Table - 3]. 
Retrieval of Video Contents based on Deep Parameter Analysis using Machine Learning

TABLE III

MOVING OBJECT DETECTION AND ANALYSIS

\begin{tabular}{|c|c|c|c|}
\hline $\begin{array}{l}\text { Dataset } \\
\text { Name }\end{array}$ & $\begin{array}{l}\text { Searchi } \\
\text { ng } \\
\text { Content } \\
\text { Name } \\
\end{array}$ & $\begin{array}{l}\text { Match Factor } \\
\text { Moving Object } \\
\text { (As low as } \\
\text { better) }\end{array}$ & $\begin{array}{l}\text { Match } \\
\text { Result }\end{array}$ \\
\hline $\begin{array}{c}\text { BBC } \\
\text { Eastender } \\
\mathrm{s} \\
\end{array}$ & $\begin{array}{c}\text { Video } \\
\text { Data - } 1\end{array}$ & 252 & Match \\
\hline Flickr & $\begin{array}{c}\text { Video } \\
\text { Data - } 2\end{array}$ & 252 & Match \\
\hline IACC. 3 & $\begin{array}{c}\text { Video } \\
\text { Data - } 3\end{array}$ & 10781 & Match \\
\hline Flickr & $\begin{array}{c}\text { Video } \\
\text { Data - } 4\end{array}$ & 10781 & Match \\
\hline $\begin{array}{c}\text { BBC } \\
\text { Eastender } \\
\mathrm{s} \\
\end{array}$ & $\begin{array}{c}\text { Video } \\
\text { Data - } 2\end{array}$ & 11033 & Match \\
\hline IACC. 3 & $\begin{array}{c}\text { Video } \\
\text { Data - } 3\end{array}$ & 11033 & Match \\
\hline $\begin{array}{c}\text { BBC } \\
\text { Eastender } \\
\mathrm{s} \\
\end{array}$ & $\begin{array}{c}\text { Video } \\
\text { Data - } 4\end{array}$ & 11335 & $\begin{array}{c}\text { No } \\
\text { Match }\end{array}$ \\
\hline i-LIDS & $\begin{array}{c}\text { Video } \\
\text { Data - } 1 \\
\end{array}$ & 11335 & $\begin{array}{c}\text { No } \\
\text { Match }\end{array}$ \\
\hline i-LIDS & $\begin{array}{c}\text { Video } \\
\text { Data - } 3\end{array}$ & 11587 & $\begin{array}{c}\text { No } \\
\text { Match }\end{array}$ \\
\hline Flickr & $\begin{array}{c}\text { Video } \\
\text { Data - } 4\end{array}$ & 11587 & $\begin{array}{c}\text { No } \\
\text { Match }\end{array}$ \\
\hline IACC. 3 & $\begin{array}{c}\text { Video } \\
\text { Data - } 1\end{array}$ & 22368 & $\begin{array}{c}\text { No } \\
\text { Match }\end{array}$ \\
\hline i-LIDS & $\begin{array}{c}\text { Video } \\
\text { Data - } 2\end{array}$ & 22368 & $\begin{array}{c}\text { No } \\
\text { Match }\end{array}$ \\
\hline
\end{tabular}

The result is visualized graphically here [Fig -3$]$.

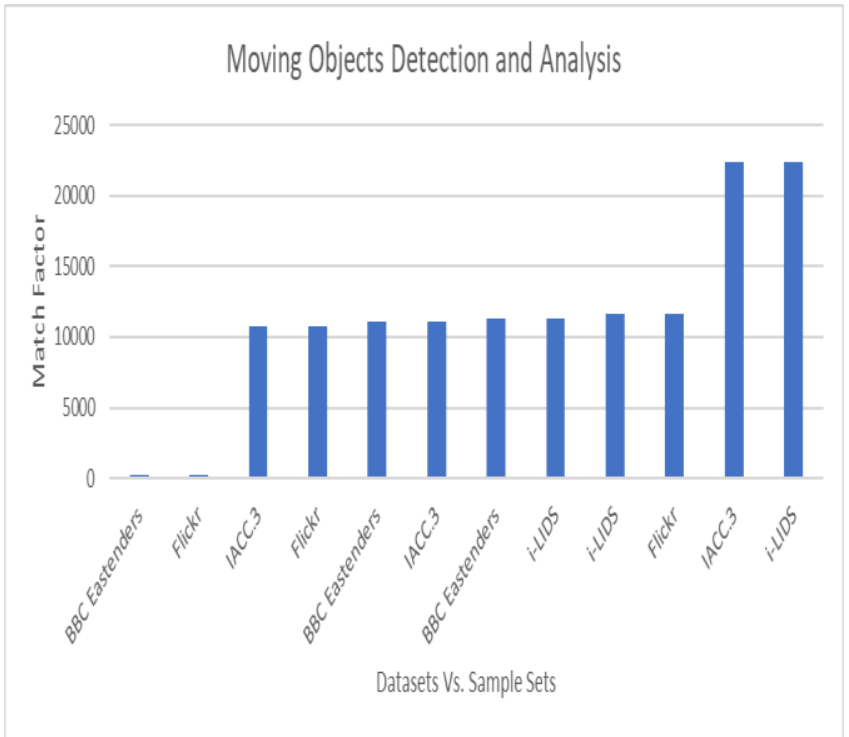

Fig. 3Moving Object Analysis and Match Factor

\section{Faster Moving Object Analysis}

The details of the faster moving object detection and analysis is listed here [Table-4].
TABLE IV

FASTER MOVING OBJECT DETECTION AND ANALYSIS

\begin{tabular}{|c|c|c|c|}
\hline $\begin{array}{l}\text { Dataset } \\
\text { Name }\end{array}$ & $\begin{array}{l}\text { Searchin } \\
\text { g Content } \\
\text { Name }\end{array}$ & $\begin{array}{l}\text { Match } \\
\text { Factor } \\
\text { Faster } \\
\text { Moving } \\
\text { Object (As } \\
\text { low as better) }\end{array}$ & $\begin{array}{l}\text { Match } \\
\text { Result }\end{array}$ \\
\hline $\begin{array}{c}\text { BBC } \\
\text { Eastenders }\end{array}$ & $\begin{array}{c}\text { Video } \\
\text { Data - } 1\end{array}$ & 383 & Match \\
\hline Flickr & $\begin{array}{c}\text { Video } \\
\text { Data - } 2\end{array}$ & 383 & Match \\
\hline IACC. 3 & $\begin{array}{c}\text { Video } \\
\text { Data - } 3\end{array}$ & 3545 & Match \\
\hline Flickr & $\begin{array}{c}\text { Video } \\
\text { Data - } 4\end{array}$ & 3545 & Match \\
\hline $\begin{array}{c}\text { BBC } \\
\text { Eastenders }\end{array}$ & $\begin{array}{c}\text { Video } \\
\text { Data - } 2\end{array}$ & 3928 & Match \\
\hline IACC. 3 & $\begin{array}{c}\text { Video } \\
\text { Data - } 3\end{array}$ & 3928 & Match \\
\hline $\begin{array}{c}\text { BBC } \\
\text { Eastenders }\end{array}$ & $\begin{array}{c}\text { Video } \\
\text { Data - } 4 \\
\end{array}$ & 4827 & No Match \\
\hline i-LIDS & $\begin{array}{c}\text { Video } \\
\text { Data - } 1\end{array}$ & 4827 & No Match \\
\hline i-LIDS & $\begin{array}{c}\text { Video } \\
\text { Data - } 3\end{array}$ & 5210 & No Match \\
\hline Flickr & $\begin{array}{c}\text { Video } \\
\text { Data - } 4\end{array}$ & 5210 & No Match \\
\hline IACC. 3 & $\begin{array}{c}\text { Video } \\
\text { Data - } 1\end{array}$ & 8755 & No Match \\
\hline i-LIDS & $\begin{array}{c}\text { Video } \\
\text { Data - } 2\end{array}$ & 8755 & No Match \\
\hline
\end{tabular}

The result is visualized graphically here [Fig - 4].

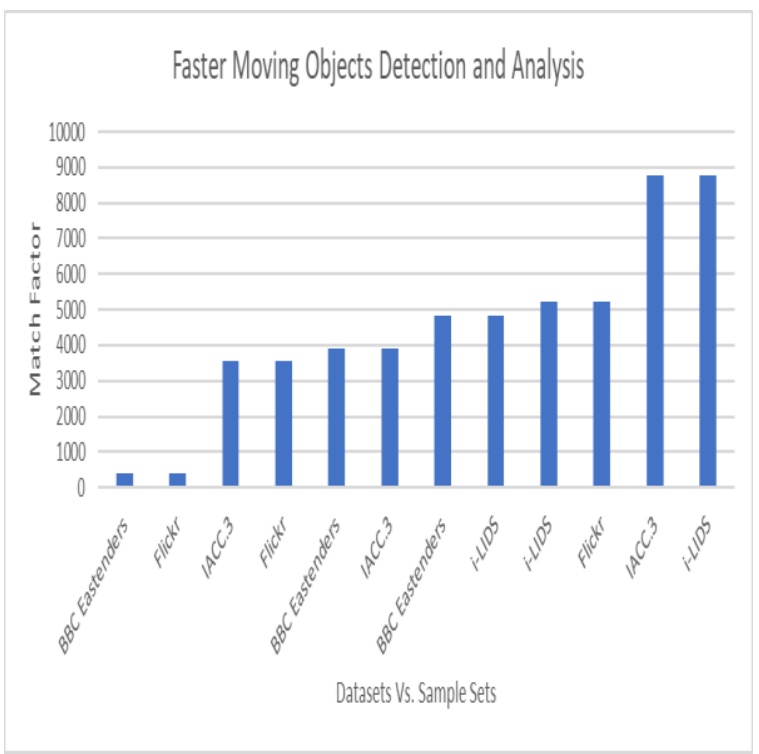

Fig. 4Faster Moving Object Analysis and Match Factor

\section{E. Faster Moving Object Area Analysis}

The details of the faster moving object area detection and analysis is listed here [Table-5].

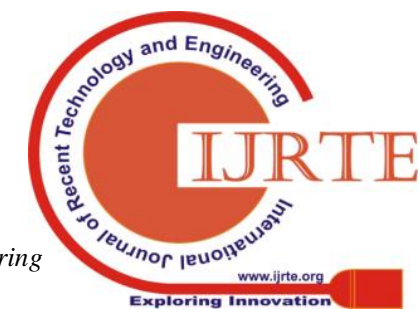


TABLE V

FASTER MOVING OBJECT AREA DETECTION AND ANALYSIS

\begin{tabular}{|c|c|c|c|}
\hline Dataset Name & $\begin{array}{l}\text { Searching } \\
\text { Content } \\
\text { Name }\end{array}$ & $\begin{array}{l}\text { Match } \\
\text { Factor } \\
\text { Faster } \\
\text { Moving } \\
\text { Object } \\
\text { Area(As } \\
\text { low as } \\
\text { better) }\end{array}$ & $\begin{array}{l}\text { Match } \\
\text { Result }\end{array}$ \\
\hline $\begin{array}{c}\text { BBC } \\
\text { Eastenders }\end{array}$ & $\begin{array}{c}\text { Video Data } \\
-1\end{array}$ & 1.693 & Match \\
\hline Flickr & $\begin{array}{c}\text { Video Data } \\
-2\end{array}$ & 1.693 & Match \\
\hline IACC. 3 & $\begin{array}{c}\text { Video Data } \\
-3\end{array}$ & 12.651 & Match \\
\hline Flickr & $\begin{array}{c}\text { Video Data } \\
-4\end{array}$ & 12.651 & Match \\
\hline $\begin{array}{c}\text { BBC } \\
\text { Eastenders }\end{array}$ & $\begin{array}{c}\text { Video Data } \\
-2\end{array}$ & 14.343 & Match \\
\hline IACC. 3 & $\begin{array}{c}\text { Video Data } \\
-3\end{array}$ & 14.343 & Match \\
\hline $\begin{array}{c}\text { BBC } \\
\text { Eastenders }\end{array}$ & $\begin{array}{c}\text { Video Data } \\
-4\end{array}$ & 16.881 & No Match \\
\hline i-LIDS & $\begin{array}{c}\text { Video Data } \\
-1\end{array}$ & 16.881 & No Match \\
\hline i-LIDS & $\begin{array}{c}\text { Video Data } \\
-3 \\
\end{array}$ & 18.574 & No Match \\
\hline Flickr & $\begin{array}{c}\text { Video Data } \\
-4 \\
\end{array}$ & 18.574 & No Match \\
\hline IACC. 3 & $\begin{array}{c}\text { Video Data } \\
-1\end{array}$ & 31.224 & No Match \\
\hline i-LIDS & $\begin{array}{c}\text { Video Data } \\
-2 \\
\end{array}$ & 31.224 & No Match \\
\hline
\end{tabular}

The result is visualized graphically here [Fig - 5].

\section{Faster Moving Objects Area Detection and Analysis}

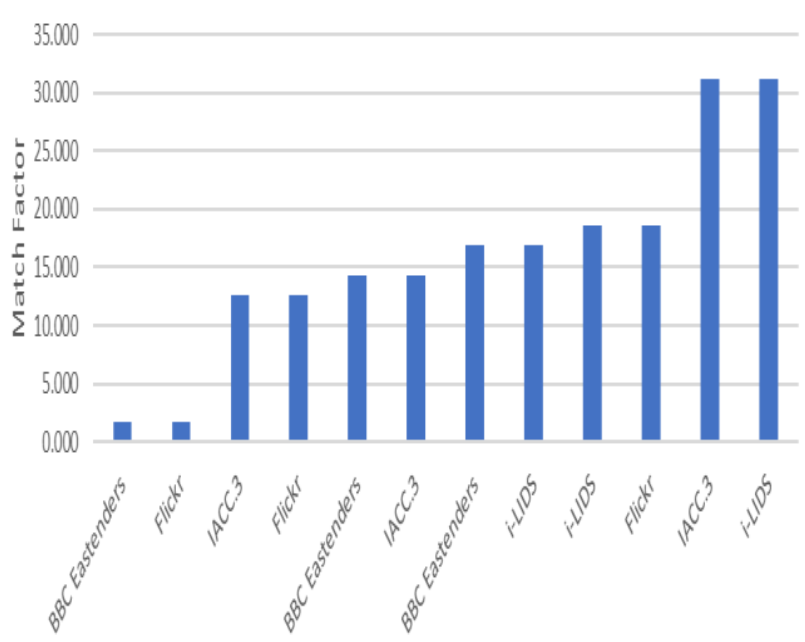

Datasets Vs. Sample Sets

Fig. 5 Faster Moving Object Area Analysis and Match Factor

\section{F. Video Retrieval Result} $-6]$.

The final video retrieval results are furnished here [Table
TABLE VI

VIDEO DATA RETRIEVAL ANALYSIS

\begin{tabular}{|c|c|c|c|c|c|c|c|c|}
\hline $\begin{array}{c}\text { Dataset } \\
\text { Name }\end{array}$ & $\begin{array}{c}\text { Searching } \\
\text { Content } \\
\text { Name }\end{array}$ & $\begin{array}{l}\text { StaticObjects } \\
\text { Match } \\
\text { Result }\end{array}$ & $\begin{array}{l}\text { Moving } \\
\text { Objects } \\
\text { Match } \\
\text { Result }\end{array}$ & $\begin{array}{c}\text { Fast } \\
\text { Moving } \\
\text { Objects } \\
\text { Match } \\
\text { Result }\end{array}$ & $\begin{array}{c}\text { Fast } \\
\text { Moving } \\
\text { Objects } \\
\text { Area } \\
\text { Match } \\
\text { Result } \\
\end{array}$ & $\begin{array}{c}\text { Dataset } \\
\text { Classification }\end{array}$ & $\begin{array}{c}\text { Proposed } \\
\text { Method } \\
\text { Classification }\end{array}$ & $\begin{array}{c}\text { Accuracy } \\
(\%)\end{array}$ \\
\hline \begin{tabular}{|c|} 
BBC \\
Eastenders
\end{tabular} & $\begin{array}{c}\text { Video Data - } \\
1\end{array}$ & Match & Match & Match & Match & Match & Match & 100 \\
\hline Flickr & $\begin{array}{c}\text { Video Data - } \\
2\end{array}$ & Match & Match & Match & Match & Match & Match & 100 \\
\hline IACC. 3 & $\begin{array}{c}\text { Video Data - } \\
3\end{array}$ & Match & Match & Match & Match & Match & Match & 100 \\
\hline Flickr & $\begin{array}{c}\text { Video Data - } \\
4\end{array}$ & Match & Match & Match & Match & Match & Match & 100 \\
\hline \begin{tabular}{|c|} 
BBC \\
Eastenders
\end{tabular} & $\begin{array}{c}\text { Video Data - } \\
2\end{array}$ & Match & Match & Match & Match & Match & Match & 100 \\
\hline IACC. 3 & $\begin{array}{c}\text { Video Data - } \\
3\end{array}$ & Match & Match & Match & Match & Match & Match & 100 \\
\hline \begin{tabular}{|c|}
$\mathrm{BBC}$ \\
Eastenders \\
\end{tabular} & $\begin{array}{c}\text { Video Data - } \\
4\end{array}$ & No Match & $\begin{array}{c}\text { No } \\
\text { Match }\end{array}$ & No Match & No Match & No Match & No Match & 95 \\
\hline i-LIDS & $\begin{array}{c}\text { Video Data - } \\
1\end{array}$ & No Match & $\begin{array}{c}\text { No } \\
\text { Match }\end{array}$ & No Match & No Match & No Match & No Match & 95 \\
\hline i-LIDS & $\begin{array}{c}\text { Video Data - } \\
3\end{array}$ & No Match & $\begin{array}{c}\begin{array}{c}\text { No } \\
\text { Match }\end{array} \\
\end{array}$ & No Match & No Match & No Match & No Match & 95 \\
\hline Flickr & $\begin{array}{c}\text { Video Data - } \\
4 \\
\end{array}$ & No Match & $\begin{array}{c}\text { No } \\
\text { Match }\end{array}$ & No Match & No Match & No Match & No Match & 100 \\
\hline IACC. 3 & $\begin{array}{c}\text { Video Data - } \\
1 \\
\end{array}$ & No Match & $\begin{array}{c}\text { No } \\
\text { Match }\end{array}$ & No Match & No Match & No Match & No Match & 95 \\
\hline i-LIDS & $\begin{array}{c}\text { Video Data - } \\
2\end{array}$ & No Match & $\begin{array}{c}\text { No } \\
\text { Match }\end{array}$ & No Match & No Match & No Match & No Match & 100 \\
\hline
\end{tabular}

Thus, the proposed method demonstrates a $100 \%$ accuracy for the video content retrieval.

Henceforth, with the detailed analysis of the results obtained from the proposed algorithms, in the next section of the work, the conclusion is presented.

\section{CONCLUSION}

The video retrieval from the video data library has become one of the prime research objectives due to the increase in usage of video content in various purposes. The standard methods for video data retrieval are criticised for lower accuracy and higher time complexity. The fundamental drawbacks of the existing method are to depend on the primitive characteristics such as colour, shape or position of the objects, which are prone to be less accurate due to higher dependencies on stabilization of the frames, colour intensity and variation of the background. Hence, this work identifies the demand for the enhancements of parameter extraction from the video frames. The identified deep characteristics parameters from the videos such as static objects characteristics and moving objects characteristics are extracted for identification and analysis. Further, the moving objects are also classified into a newer category as faster moving objects to identify the frame rate change for tracking of objects converting from static to moving objects. Also, the reference of frames is made static considering the change in area for the faster moving objects. Henceforth, considering the deep characteristics of the video data, this work finally deploys an algorithm to identify the similarity and retrieve the matching video content from the video library using deep machine learning characterises. The final outcome of this work is to retrieve the video data based on video segment inputs. The work is tested on four different standard datasets and produce nearly $98 \%$ accuracy.

\section{REFERENCES}

1. Ekermo, V. Norell, "Reducing the need for manual cleaning maintenance of digital surveillance cameras-A conceptual study", 2013.

Published By:

Blue Eyes Intelligence Engineering \& Sciences Publication 
2. Y. M. E. Candes, X. Li, J. Wright, "Robust principal component analysis", J. ACM, vol. 58, no. 3, pp. 11-20, 2011.

3. Lu, J. Feng, Y. Chen, W. Liu, Z. Lin, S. Yan, "Tensor robust principal component analysis: Exact recovery of corrupted low-rank tensors via convex optimization", Proc. IEEE Conf. Comput. Vision Pattern Recognit., pp. 5249-5257, 2016.

4. X. Liu, G. Zhao, J. Yao, C. Qi, "Background subtraction based on low-rank and structured sparse decomposition", IEEE Trans. Image Process., vol. 24, no. 8, pp. 2502-2514, Aug. 2015.

5. X. Zhou, C. Yang, W. Yu, "Moving object detection by detecting contiguous outliers in the low-rank representation", IEEE Trans. Pattern Anal. Mach. Intell., vol. 35, no. 3, pp. 597-610, Mar. 2013.

6. X. Zhang, C. Zhu, S. Wang, Y. Liu, M. Ye, "A Bayesian approach to camouflaged moving object detection", IEEE Trans. Circuits Syst. Video Technol., vol. 27, no. 9, pp. 2001-2013, Sep. 2017.

7. O. Oreifej, X. Li, M. Shah, "Simultaneous video stabilization and moving object detection in turbulence", IEEE Trans. Pattern Anal. Mach. Intell., vol. 35, no. 2, pp. 450-462, Feb. 2013.

8. W. Cao et al., "Total variation regularized tensor RPCA for background subtraction from compressive measurements", IEEE Trans. Image Process., vol. 25, no. 9, pp. 4075-4090, Sep. 2016.

9. X. Cao, L. Yang, X. Guo, "Total variation regularized RPCA for irregularly moving object detection under dynamic background", IEEE Trans. Cybern., vol. 46, no. 4, pp. 1014-1027, Apr. 2016.

10. Yong, D. Meng, W. Zuo, L. Zhang, "Robust online matrix factorization for dynamic background subtraction", IEEE Trans. Pattern Anal. Mach. Intell., vol. 40, no. 7, pp. 1726-1740, Jul. 2018.

11. L. Li, P. Wang, Q. Hu, S. Cai, "Efficient background modeling based on sparse representation and outlier iterative removal", IEEE Trans. Circuits Syst. Video Technol., vol. 26, no. 2, pp. 278-289, Feb. 2016. 